\title{
How do Age And Location AFFect a Business? Evaluating THE OBJectives, OUTPUTS ANd OUTCOMES of Small Business Policy
}

\author{
Menisha Moos and Melodi Botha \\ Department of Business Management, University of Pretoria \\ Accepted: March 2016
}

\begin{abstract}
Many scholars have dedicated their studies to understanding the kind of assistance given to small business. Likewise, numerous studies have concentrated on how government in particular, through a small business policy, can be instrumental in providing business support. This article evaluates South Africa's small business policy by concentrating on its objectives, outputs and outcomes. Studies evaluating small business policy according to its objectives, outputs and outcomes, have been limited. Such policy evaluation goes beyond merely reporting to understanding why certain phenomena take place. As an emerging economy, South Africa is in dire need of well-developed policies. This article proposes that understanding the link between small business policy and the age and location of a business may help government to refine policy formulation and design. Using a survey method and cross-sectional research design, the sample size of 340 respondents consisted of start-up and established business owners. This study found that not the age of the business, but only its location (the metropolitan municipality where the business is located) has a statistically significant effect on the objectives, outputs and outcomes of the small business policy. These findings should assist both national and international policymakers to identify specific context-bound interventions relevant to the location of businesses with a view to improving them.
\end{abstract}

Key words: South Africa, business age, business location, objectives, outputs and outcomes of small business policy, policy evaluation

JEL: L530

\section{Introduction}

Many scholars have dedicated their studies to understanding small business support (Van Vuuren \& Groenewald, 2007:269; Stevenson \& Lundström, 2007:105; Ijeoma \& Matarirano, 2011:863; Luiz \& Mariotti, 2011:62; Peters \& Naicker, 2013:13). Likewise, numerous studies have concentrated on how government in particular, through a small business policy, can be instrumental in providing business support (Lundström \& Stevenson, 2001:137; Audretsch, 2005:21; Kirby, 2005:558; Acs \& Szerb, 2006:111; Hemphill, 2005:476; Minniti, 2008:787; Westhead et al., 2011:3; Niska \& Vesala, 2013:521; Ligthelm, 2013:73; Watson, 2013:407). This paper evaluates South Africa's small business policy by concentrating on the objectives, outputs and outcomes of such a policy. Only limited studies have addressed small business policy evaluation according to its objectives, outputs and outcomes (Stevenson \& Lundström, 2007:105107; Robson et al., 2009:531). This approach tests the effects of the small business policy in terms of its transparency, necessity, efficiency, appropriateness and validity (Cloete, 2009:295; Engela \& Ajam, 2010:26). The policy's intended results in the form of outputs, outcomes or impacts are measured against envisaged goals and objectives (Policy Hub, 2010:3; Ile et al., 2012:43). This form of policy evaluation goes beyond merely reporting to understanding why certain phenomena take place (Cloete, 2009:295; Engela \& Ajam, 2010:26).

This article furthermore highlights the age and location of a business when evaluating small business policy. It is imperative to understand the link between small business policy and the age and location of businesses. Businesses differ in terms of the number of years they have been in operation, as well as their location, associated resources and market capabilities. 'Age' classifies a business as either a start-up or an established business. The age of a business venture has 
important implications for a small business policy, because it has to accommodate the array of needs of both start-up and established businesses. A start-up business venture refers to a new business which has been in operation for less than 3.5 years, whereas an established business venture has been in operation for more than 3.5 years (Herrington et al., 2010:10; Turton \& Herrington, 2013:15). Van Vuuren and Groenewald (2007:269) stress that policymakers at different levels of government should take note that start-up and established businesses have different needs and require different support, depending upon where they are in the life cycle of their venture. Policymakers and practitioners have to seek different strategies to promote and increase the supply of start-up and established business owners.

Many studies of which Bruton et al. (2008:11) is one example, have tended to assume that entrepreneurs think and act similarly, irrespective of where they are located. In this view, there is little significant diversity in the cultural and institutional contexts of different countries where entrepreneurs operate. However, this is not the case in practice. It is important to examine the context within which small business and entrepreneurial activities are performed (Watson, 2013:405). In this article, small business policy is evaluated by start-up and established businesses located in the metropolitan municipalities of the City of Cape Town, the City of eThekwini, the City of Ekurhuleni, the City of Johannesburg and the City of Tshwane in South Africa. Local differences within a country require that policies be designed to adapt to the nature of existing resources, networks and market capabilities of the area (Brynard, 2007:357).

The research problem addressed in this article, therefore, is to evaluate the small business policy objectives, outputs and outcomes to determine the extent to which the different age categories and location of businesses are considered in the policy. The article commences with the theoretical foundation by discussing policies: South Africa's small business policy and the relevance of age and location to a business. The hypotheses that guided the research are stated, followed by the research methodology used to collect and analyse data, the results and discussions thereof, as well as the contributions and limitations of this study.

\section{Theoretical foundation}

Policies are crucial for shaping small business and entrepreneurial behaviour. The results of such policies have been mixed and researchers have not been able to tackle this issue satisfactorily (Minniti, 2008:779-781). Policies fail or succeed partially. Uncovering relevant factors can add to their success or failure and may be helpful to policymakers when adjusting them.

\subsection{Defining policies}

A policy is a programme of action to give effect to specific goals and objectives aimed at changing (and preferably improving) an existing unsatisfactory situation, such as that of small business and entrepreneurial activity (Cloete, 2009:294). Policy evaluation differs from policy monitoring because it goes beyond merely reporting to understanding why phenomena take place. It checks the effects of policies in terms of their transparency, necessity, efficiency, appropriateness and validity (Engela \& Ajam, 2010:26).

A small business policy aims to maintain and grow existing small and medium enterprises (SMEs) by means of funding, training and advisory services (Niska \& Vesala, 2013:524), whereas an entrepreneurship policy directly influences the level of entrepreneurial activity in a country or region (Stevenson \& Lundström, 2007:107).

\subsection{Small business policy in South Africa}

As a developing country, South Africa needs an effective policy that will address the needs of small businesses and shape entrepreneurial actions (Ligthelm, 2013:73; Watson, 2013:407). So far the success of the small business policy has been hampered by a lack of awareness of the various initiatives and poor service levels (Peters \& Naicker, 2013:20). The National Small Business Act (Act No. 102 of 1996) as amended, has formed the cornerstone of South Africa's small business 
policy (RSA, 1996). The Integrated Strategy on the Promotion of Entrepreneurship and Small Enterprises (ISPESE) was introduced as a strategic framework from 2005 to 2014 to foster entrepreneurship and promote small enterprise in South Africa for a period of ten years (dti, 2005a:ii).

\subsection{Objectives, outputs and outcomes of a small business policy}

The primary objective of a small business policy is to create an enabling environment for small enterprises (dti, 2005a:7) and to stimulate the growth and development of a small, medium and micro enterprises (SMME) sector (Ligthelm, 2013:58; Gwija et al., 2014:61). Outputs may include the establishment of a dedicated network of SMME finance and the provision of the necessary support incentives (dti, 2005b:iii). The overall outcomes pursued entail creating employment, fostering economic growth, improving competitiveness and regional/structural development (Niska \& Vesala, 2013:524). Different scholars have conducted research to develop small business policy objectives, outputs and outcomes (Lundström \& Stevenson; 2005:51; Audretsch, 2005:32; Stevenson \& Lundström, 2007:105-107; Van Stel et al., 2007:3; Robson et al., 2009:531; Niska \& Vesala, 2013:524). Government documents, reports and national strategies were also consulted to gather information regarding objectives (refer to Annexure A for the comprehensive compilation of the objectives), outputs (refer to Annexure B) and outcomes (refer to Annexure C) of South Africa's small business policy (dti, 1995:16; dti, 2005b:iii; DPLG, 2006:23).

\subsection{Small business policy and age of a business}

Botha (2014:25) defines an individual who commences operations within a new business venture as a start-up business owner. Salaries, wages or any other payments to its owners have been made for more than three (3) months, but not more than 42 months or 3.5 years. An established business, on the other hand, is operated and managed by an established business owner who has been in a position to pay salaries, wages, or any other payments to the owners for more than 42 months or 3.5 years (Turton \& Herrington, 2013:15). GEM 2012 reported that the start-up or new business ownership rate in South Africa was 7.3 per cent, whereas the established business ownership rate was 2.3 per cent (Turton \& Herrington, 2013:53). South Africa still lags behind other developing countries in encouraging more successful entrepreneurs, both in start-up as well as established businesses (Themba, 2012:5; Gwija et al., 2014:63).

At the pre-start-up stage, support measures such as reducing entry/exit barriers, improving access to finance, advice, networks and mentoring are imperative (Ligthelm, 2013:62). The post start-up stage (start-up to 3.5 years) requires more attention to promoting growth possibilities, development of business management/growth skills and measures to level the playing field (Stevenson \& Lundström, 2007:105). Regulatory and labour market obstacles should be reduced and new business possibilities promoted. As an established business from 3.5 years and onwards, the business needs to be maintained and grown by means of funding, training and advisory services (Niska \& Vesala, 2013:524).

With better preparation and increased exposure to the entrepreneurial process prior to starting an entrepreneurial career, new business owners would be more likely to realise the full potential of their businesses. Besides this, more tailored and individualised support during the vulnerable years is considered to be vital for survival. Therefore, being more informed, knowledgeable and competent can make a huge difference to the performance of start-up businesses, and later to established ones. The policymakers' duty is to recognise these different requirements and consider them when compiling small business policy objectives, outputs and outcomes. This argument leads to the formulation of Hypothesis 1 to be tested statistically:

Hypothesis 1:

The age of a business has an effect on the:

(a) Objectives of the small business policy 
(b) Outputs of the small business policy

(c) Outcomes of the small business policy

\subsection{Small business policy and the location of a business}

Location plays an important role in the establishment of the business (Nieman \& Nieuwenhuizen, 2014:176). 'Location' refers to the physical establishment or premises within a specific geographical area from where a business is operating / trading and managing activities. This study specifically investigated start-up and established businesses located in three provinces (Gauteng, the Western Cape and KwaZulu-Natal) in South Africa, considered to be the growth nodes for the economy (Herrington et al., 2010:44). Gauteng contributes a gross domestic product (GDP) share of 34.5 per cent to the national economy, KwaZulu-Natal 16.5 per cent and the Western Cape 14.2 per cent (GED, 2013:1). Within the provinces the selected metropolitan municipalities of the City of Cape Town, Ekurhuleni Metropolitan Municipality (East Rand), the City of eThekwini (Durban), the City of Johannesburg and the City of Tshwane (Pretoria) are included in the study. The reason for selecting these five metropolitan municipalities is because they provide the ideal locations for entrepreneurs to establish their premises (Herrington et al., 2010:44).

In this article, the importance of location of start-up and established businesses within the different metropolitan municipalities in South Africa is acknowledged. The aim is to determine the effect of the factor of location on the objectives, outputs and outcomes of the small business policy. Start-up and established business owners face different challenges in the metropolitan municipalities, such as over-regulation, time-consuming red tape and very costly bureaucratic processes. Government is out of touch with entrepreneurs and national government support is not sufficient for small businesses in Johannesburg. Statistics show that Cape Town and the Western Cape have a much better survival rate for small business owners than Johannesburg (Peyper, 2012:1).

From a practical perspective, policies encouraging small business, entrepreneurship and economic regeneration need to be more flexible and sensitive to the start-up and established business owner's managerial capabilities, experience and identity, as well as to the specific location and activity in which the business is embedded and engaged (Thorpe et al., 2005:257; Luiz \& Mariotti, 2011:62).

The above argument leads to the formulation of Hypothesis 2 to be tested statistically:

Hypothesis 2:

The location (metropolitan municipality) of a business has an effect on the:

(a) Objectives of the small business policy

(b) Outputs of the small business policy

(c) Outcomes of the small business policy

\section{Research methodology}

A cross-sectional research design was used to collect data at a particular point in time (Cooper \& Schindler, 2011:140). In the survey administered to the start-up and established businesses, owners were asked to rate the extent of their level of agreement with the objectives, outputs and outcomes of the small business policy with a set of statements. A five-point Likert scale ranging from $1=$ 'definitely disagree' to $5=$ 'definitely agree' was used to measure the variables.

Respondents were interviewed in three provinces, namely Gauteng, KwaZulu-Natal and the Western Cape. The survey was modified after a pilot study had been carried out on five start-up / established business owners who met the target population requirements. A group of experts including academics were also requested to comment on the survey design and structure. The pilot test respondents were excluded from the final analysis. 
Two sampling methods were used for this study. A systematic probability sampling method was initially used to select the start-up / established business owners. Through this method 127 start-up / established business owners completed surveys. After reviewing the completeness of the questionnaires, 123 questionnaires were retained with a response rate of 97 per cent. This sample was considered inadequate to proceed with the data analysis. Therefore, the purposive nonprobability sampling method was used in an attempt to meet the total sample size requirements. For this sampling method, start-up / established business owners were arbitrarily and subjectively selected, based on their adherence to the target population requirements (Cooper \& Schindler, 2011:385). By means of the purposive non-probability sampling method, 244 start-up / established business owners were interviewed, of which 217 questionnaires were retained with a response rate of 89 per cent. In total, 340 start-up / established business owners were included in the data analysis.

\subsection{Data analysis}

The factor analysis results for the respondents' evaluation of the objectives, outputs and outcomes of South Africa's small business policy are displayed in Table 1. Maximum likelihood factor analysis and direct quartimin rotation were used.

Table 1

Factor analysis results

\begin{tabular}{|l|c|c|c|}
\hline \multicolumn{1}{|c|}{ Factor } & Eigen value & Cronbach Alpha & Variance explained \\
\hline Objectives & 4.60634 & 0.8569 & $41.08 \%$ \\
\hline Outputs & 2.37948 & 0.8691 & $69.97 \%$ \\
\hline Outcomes & 4.62387 & 0.8804 & $45.46 \%$ \\
\hline
\end{tabular}

These factors confirm the construct validity of the questionnaire. Reliability, through the use of the Cronbach Alpha coefficient, was also confirmed.

A General Linear Model (GLM) was used to determine the statistically significant effect of (i) the age of the business (start-up / established businesses), and (ii) the location (in which metropolitan municipality it was situated), as well as the interaction effect between these factors, with regard to the objectives, outputs and outcomes represented through the factor scores that were calculated as the average of the variables constituting each factor.

For this study, the analysis of variance (ANOVA) was used to test whether more than two independent sample means are equal. It uses a single-factor, fixed-effects model to compare the effects of one variable or factor on a continuous dependent variable. The use of ANOVA requires the verification of two assumptions: (1) normal distribution of the dependent variable for each category of the independent variable; and (2) equal variances (Cooper \& Schindler, 2011:478; Diamantopoulos \& Schlegelmilch, 2000:187). These assumptions were tested and the results showed that this was not the case. Therefore, a 'Normal Blom Transformation' was conducted, which then resulted in the assumptions being met and the study could continue with the execution of an ANOVA. Transformations are usually applied so that the data appears to more closely meet the assumptions of a statistical inference procedure that is to be applied. The test statistic for ANOVA is the $F$ ratio. When a normal distribution cannot be assumed, a nonparametric method, the Kruskal-Wallis one-way ANOVA test, can be used. Nonparametric tests have fewer and less stringent assumptions than parametric tests (Cooper \& Schindler, 2011:675).

\section{Results}

\subsection{Demographic data}

The sample consists of 176 male (51.92 per cent) and 163 female (48.08 per cent) respondents. One respondent did not complete the question on gender. The finance and business services sector attracted 65 start-up / established business owners (20.25 per cent). Seventy six (76) respondents 
(23.68 per cent) were in the retail, motor trade and repair services sector. A total of 220 Black African (65.67 per cent); 70 White (20.90 per cent); 26 Coloured (7.76 per cent) and 18 Indian start-up / established business owners were included in the sample.

From the total sample (337) of start-up / established business owners who completed this question, 222 (65.88 per cent) were located in the City of Tshwane; 40 in the City of Cape Town (17.51 per cent) and 59 respondents were from the City of eThekwini (11.87 per cent). The remaining respondents were from the cities of Ekurhuleni (6) and Johannesburg (10). A total of 187 of the business ventures (57.01 per cent) included in the sample were start-up businesses, which means that they were younger than 3.5 years. The remaining 141 respondents $(42.99$ per cent) indicated that their business ventures were 3.5 years and older, and so these ventures were termed established businesses. Twelve (12) respondents did not indicate the age of their business ventures.

The next section will present the inferential statistics and will be described according to the hypotheses as previously stated. In this study, the small business policy evaluation of the objectives, outputs and outcomes is the dependent variable. The number of years the business has been in operation (its age) and its location in the metropolitan municipality are the independent variables.

\subsection{Inferential statistics used to test Hypotheses 1(a) and 2(a)}

The GLM test aims to determine the statistically significant effect of (i) the age of the business (start-up / established business), and (ii) its location (the metropolitan municipality into which the business falls), as well as the interaction effect between these factors, with regard to the objectives of the small business policy. The GLM result for the objectives factor is presented in Table 2 . The standard way of summarising the results of a GLM contains the sources of variation, the degrees of freedom, sum of squares, mean squares and calculated F-value.

Table 2

General Linear Model result for the factor "Objectives of the small business policy" as dependent variable

\begin{tabular}{|l|r|c|c|c|c|}
\hline \multicolumn{1}{|c|}{ Source } & DF & Sum of squares & Mean square & F value & P value \\
\hline Model & 5 & 46.9029658 & 9.3805932 & 10.80 & $<0.0001^{*}$ \\
\hline Error & 317 & 275.4043280 & 0.8687834 & & \\
\hline Corrected total & 322 & 322.3072938 & & & \\
\hline
\end{tabular}

*Statistically significant at $\alpha=0.0001$, Confidence interval: 99 per cent

The results in Table 2 indicate that the model is statistically significant at the 1 per cent level of significance $(\alpha=0.01)$. The p-value of less than 0.0001 illustrates a statistically significant effect for the objectives factor and the independent variables. However, the exact independent variable (age or the metropolitan municipality where the business is located) is not evident. Therefore, an ANOVA test was conducted and the results for each of the effect variables as well as the interaction effect are shown in Table 3.

Table 3

Tests of Between-Subjects effects for the factor "Objectives of the small business policy" as dependent variable

\begin{tabular}{|l|c|c|c|c|c|}
\hline \multicolumn{1}{|c|}{ Independent variable } & DF & $\begin{array}{c}\text { Sum of } \\
\text { squares }\end{array}$ & Mean square & F value & P value \\
\hline Age of the business & 1 & 0.46261395 & 0.46261395 & 0.53 & 0.4661 \\
\hline Location (Metropolitan municipality) $^{\prime}$ & 2 & 36.34900756 & 18.17450378 & 20.92 & $<0.0001^{*}$ \\
\hline Interaction effect: & & & & 0.24 & 0.7832 \\
\hline
\end{tabular}

*Statistically significant at $\alpha=0.0001$, Confidence interval: $99 \%$

Interaction effect between age of business and location (metropolitan municipality)

Using a significance level of 1 per cent $(\alpha=0.01)$, the results show that only the location (metropolitan municipality) variable has a statistically significant effect $(p<0.0001)$ with regard 
to the objectives of the small business policy. The objectives of the small business policy are viewed and interpreted differently in the different provinces and therefore in the different metropolitan municipalities. The age of the business $(\mathrm{p}=0.4661)$ as well as the interaction effect between age of business and metropolitan municipality $(p=0.7832)$ has no statistically significant effect with regard to the objectives of the small business policy. This means that there is no statistically significant effect between the start-up and established business owners with regard to their viewpoints of the objectives of the small business policy.

The differences between each possible pair of the metropolitan municipality groups were further examined. Table 4 indicates the significantly different stratification group means at a specified level.

Table 4

Variables that show significant differences regarding the objectives of the small business policy for the start-up / established business owners group

\begin{tabular}{|l|c|c|c|}
\hline \multicolumn{1}{|c|}{ Variable } & N & Mean & Standard deviation \\
\hline Location (Metropolitan municipality) & 57 & 3.13684211 & 0.91077510 \\
\hline City of Cape Town & 226 & 3.86460177 & 0.72943453 \\
\hline Cities of Ekurhuleni, Johannesburg \& Tshwane & 40 & 3.08000000 & 0.87213266 \\
\hline City of eThekwini & & \\
\hline
\end{tabular}

The results in Table 4 imply that the location of the start-up / established business owners does affect their standpoint on the objectives of the small business policy. Some of these objectives include assistance with business venture growth, targeting existing businesses rather than individuals and focusing upon creating a favourable business environment. The City of Cape Town (mean $=3.14$ ) and the City of eThekwini (mean $=3.08)$ have the closest mean scores to each other which differ sharply from the remaining metropolitan municipalities (mean $=3.86$ ). Therefore, the City of Cape Town and the City of eThekwini tend to agree more with each other regarding the objectives of the small business policy than the Cities of Ekurhuleni, Johannesburg and Tshwane. The latter metropolitan municipalities, which are located in Gauteng Province, have the most clearly defined small business objectives when compared to the Western Cape and the KwaZulu-Natal provinces.

\subsection{Inferential statistics used to test Hypotheses 1(b) and 2(b)}

The GLM test aims to determine the statistically significant effect of (i) the age of the business (start-up / established businesses), and (ii) its location (the metropolitan municipality into which the business falls), as well as the interaction effect between these factors, with regard to the outputs of the small business policy. The GLM result for the outputs factor is presented in Table 5.

Table 5

General Linear Model result for the factor "Outputs of the small business policy" as dependent variable

\begin{tabular}{|l|c|c|c|c|c|}
\hline \multicolumn{1}{|c|}{ Source } & DF & Sum of squares & Mean square & F value & P value \\
\hline Model & 5 & 25.4369460 & 5.0873892 & 5.42 & $<0.0001^{*}$ \\
\hline Error & 307 & 288.1796568 & 0.9386960 & & \\
\hline Corrected total & 312 & 313.6166028 & & & \\
\hline
\end{tabular}

*Statistically significant at $\alpha=0.0001$, Confidence interval: $99 \%$

The results in Table 5 indicate that the model is statistically significant at the 1 per cent level of significance $(\alpha=0.01)$. The p-value of less than 0.0001 illustrates a statistically significant effect for the outputs factor and the independent variables. However, the exact independent variable (age or the metropolitan municipality where the business is located) is not evident. Therefore, an ANOVA test was conducted and the results for each of the effect variables as well as the interaction effect are shown in Table 6.

Using a significance level of 1 per cent $(\alpha=0.01)$ the results show that the location (metropolitan municipality) single-handedly has a statistically significant effect $(p<0.0001)$ with regard to the outputs of the small business policy. Age of the business $(p=0.3280)$ as well as the 
interaction effect between age of business and metropolitan municipality where the business is located $(\mathrm{p}=0.6269)$ has no statistically significant effect on the outputs of the small business policy. This means that the outputs of the small business policy are viewed differently by the different metropolitan municipalities. However, the age of the business does not show any statistically significant effect. Start-up and established business owners expect similar outputs to assist with their business endeavours. The outputs of the small business policy include support services, finance and incentives that have to reach all regions of the country. The results in Table 6 indicate that there are different viewpoints regarding government's efforts and attempts to be equally successful in all the selected metropolitan municipalities.

Table 6

Tests of Between-Subjects Effects for the factor "Outputs of the small business policy" as dependent variable

\begin{tabular}{|l|c|c|c|c|c|}
\multicolumn{1}{|c|}{ Independent variable } & DF & $\begin{array}{c}\text { Sum of } \\
\text { squares }\end{array}$ & Mean square & F value & P value \\
\hline Age of the business & 1 & 0.90098257 & 0.90098257 & 0.96 & 0.3280 \\
\hline Location (Metropolitan municipality) $^{\prime}$ & 2 & 18.20540569 & 9.10270284 & 9.70 & $<0.0001^{*}$ \\
\hline Interaction effect: & & & & & \\
\hline (Age of business) \\
\hline
\end{tabular}

*Statistically significant at $\alpha=0.0001$, Confidence interval: $99 \%$

Interaction effect between age of business and location (metropolitan municipality)

The differences between each possible pair of the metropolitan municipality groups were further examined. Table 7 indicates the significantly different stratification group means at a specified level.

Table 7

Variables that show significant differences regarding the outputs of the small business policy for the start-up / established business owners group

\begin{tabular}{|c|c|c|c|}
\hline Variable & $\mathbf{N}$ & Mean & Standard deviation \\
\hline \multicolumn{4}{|l|}{ Location (Metropolitan municipality) } \\
\hline City of Cape Town & 57 & 2.7514620 & 1.20534986 \\
\hline Cities of Ekurhuleni, Johannesburg \& Tshwane & 216 & 3.37654321 & 1.18438819 \\
\hline City of eThekwini & 40 & 2.47500000 & 1.13199393 \\
\hline
\end{tabular}

The results in Table 7 imply that the location of the start-up / established business owners does affect their standpoint on the outputs of the small business policy. The City of Cape Town (mean = 2.75 ) and the City of eThekwini (mean $=2.48$ ) have the closest means to each other, while the remaining metropolitan municipalities have a much higher mean of 3.38. The Cities of Ekurhuleni, Johannesburg and Tshwane agree more than the other two metropolitan municipalities that the outputs of the small business policy are being accomplished. It is interesting to note that support services such as finance and incentives are better provided in Gauteng Province than in the Western Cape and KwaZulu-Natal. A possible reason may be that the objectives for entrepreneurship and small business development are more detailed in Gauteng Province.

\subsection{Inferential statistics used to test Hypotheses 1(c) and 2(c)}

The GLM test aims to determine the statistically significant effect of (i) the age of the business (start-up / established businesses), and (ii) its location (the metropolitan municipality into which the business is falls), as well as the interaction effect between these factors, with regard to the outcomes of the small business policy. The GLM result for the outcomes factor is presented in Table 8.

The results in Table 8 indicate that the model is statistically significant at the 5 per cent level of significance $(\alpha=0.05)$. The $\mathrm{p}$-value of 0.0004 illustrates a statistically significant effect for the outcomes factor and the independent variables. However, the exact independent variable (age or the metropolitan municipality where the business is located) is not evident. Therefore, an ANOVA 
test was conducted and the results for each of the effect variables as well as the interaction effect are shown in Table 9.

Table 8

General Linear Model result for the factor "Outcomes of the small business policy" as dependent variable

\begin{tabular}{|l|r|c|c|c|c|}
\hline \multicolumn{1}{|c|}{ Source } & DF & Sum of squares & Mean square & F value & P value \\
\hline Model & 5 & 22.2276316 & 4.4455263 & 4.65 & $0.0004^{*}$ \\
\hline Error & 314 & 300.3795448 & 0.9566228 & & \\
\hline Corrected total & 319 & 322.6071764 & & & \\
\hline
\end{tabular}

*Statistically significant at $\alpha=0.05$, Confidence interval: $95 \%$

Table 9

Tests of the Between-Subjects Effects for the factor "Outcomes of the small business policy" as dependent variable

\begin{tabular}{|l|c|c|c|c|c|}
\hline \multicolumn{1}{|c|}{ Independent variable } & DF & $\begin{array}{c}\text { Sum of } \\
\text { squares }\end{array}$ & Mean square & F value & P value \\
\hline Age of the business & 1 & 3.41581761 & 3.41581761 & 3.57 & 0.0597 \\
\hline Location (Metropolitan municipality) $^{\mid}$ & 2 & 12.28141506 & 6.14070753 & 6.42 & $0.0019^{*}$ \\
\hline $\begin{array}{l}\text { Interaction effect: } \\
\text { (Age of business) } \times \text { Location (Metropolitan municipality) }\end{array}$ & 2 & 2.11537975 & 1.05768987 & 1.11 & 0.3323 \\
\hline
\end{tabular}

*Statistically significant at $\alpha=0.01$, Confidence interval: $99 \%$

Interaction effect between age of business and location (metropolitan municipality)

Using a significance level of 5 per cent $(\alpha=0.05)$ the results show that only the metropolitan municipality where the business is located has a statistically significant effect $(p=0.0019)$ on the outcomes of the small business policy. Age of the business $(p=0.0597)$ as well as the interaction effect between age of business and metropolitan municipality $(p=0.3323)$ have no statistically significant effect on the outcomes of the small business policy. The results in Table 9 imply that the outcomes of the small business policy are influenced by the location of the business venture. Outcomes such as an improved regulatory environment, decreased business start-up obstacles and changes in youths' and women's entrepreneurial activity are perceived differently in the different metropolitan municipalities. With regard to the age of the business there are no statistically significant effects between the start-up and established businesses. Both types of business expect similar outcomes to support their business development needs.

The differences between each possible pair of the metropolitan municipality groups were further examined. Table 10 presents the significantly different stratification group means at a specified level.

Table 10

Variables that show significant differences regarding the outcomes of the small business policy for the start-up / established business owners group

\begin{tabular}{|l|r|r|l|}
\hline \multicolumn{1}{|c|}{ Variable } & n & Mean & Standard deviation \\
\hline Location (Metropolitan municipality) & 57 & 3.20662768 & 0.85692495 \\
\hline City of Cape Town & 223 & 3.72296961 & 0.82717914 \\
\hline Cities of Ekurhuleni, Johannesburg \& Tshwane & 40 & 3.35000000 & 0.88372789 \\
\hline City of eThekwini &
\end{tabular}

The results in Table 10 imply that the location of the start-up / established business owners does affect their standpoint on the outcomes of the small business policy. The City of Cape Town (mean is 3.21) and the City of eThekwini (mean $=3.35$ ) have the closest mean scores to each other compared to the remaining metropolitan municipalities (mean $=3.72$ ). The Cities of Ekurhuleni, Johannesburg and Tshwane tend to agree more than the other two metropolitan municipalities that the small business policy outcomes are being reached. This means that outcomes such as creating a demand for small enterprise products and services, and improving small enterprise competencies 
and delivery capacity, have been accomplished to a lesser extent in the City of Cape Town and the City of eThekwini than in the Cities of Ekurhuleni, Johannesburg and Tshwane. The outcomes of the small business policy should help to create a favourable business environment for all entrepreneurs and small business owners. Therefore, the outcomes are of equal importance in all the selected metropolitan municipalities where the businesses are located and should be addressed as such by the government.

\section{Discussion of the findlings}

One-way ANOVA found three statistically significant differences. The first significant finding involved the variables 'age of business' and 'location' (metropolitan municipality) and the factor 'objectives of small business policy'. Using a significance level of 1 per cent $(\alpha=0.01)$ the results show that only the 'location' (metropolitan municipality) variable has a statistically significant effect on the 'objectives of the small business policy'. The 'age of the business' $(p=0.4661)$ has no statistically significant effect.

The second significant finding involved the variables 'age of business' and 'location' (metropolitan municipality) and the factor 'outputs of small business policy'. Using a significance level of 1 per cent $(\alpha=0.01)$, the results show that the 'location' (metropolitan municipality) single-handedly has a statistically significant effect on the 'outputs of the small business policy'. The 'age of the business' ( $p=0.3280$ ) has no statistically significant effect on the 'outputs of the small business policy'.

The third significant finding involved the variables 'age of business' and 'location' (metropolitan municipality) and the factor 'outcomes of small business policy'. Using a significance level of 5 per cent $(\alpha=0.05)$ the results show that only the 'location' (metropolitan municipality) has a statistically significant effect on the 'outcomes of the small business policy'. Once again, the 'age of the business' $(p=0.0597)$ was shown to have no statistically significant effect on the 'outcomes of the small business policy'.

It can therefore be concluded that there are statistically significant differences between location (the metropolitan municipalities), but not the age of the business regarding the set objectives, outputs and outcomes of the small business policy. This result implies that the government's objectives, outputs and outcomes from which they envisage the owners of the start-up / established businesses to benefit are not all considered to be relevant and crucial by the latter for their business ventures' survival, growth and success.

Based on the tests conducted and the empirical results achieved, Hypothesis 1 is rejected. Age of business does not have a statistically significant effect on the objectives, outputs and outcomes of the small business policy. By contrast, Hypothesis 2 is accepted. The location (metropolitan municipality) does indeed have a statistically significant effect on the objectives, outputs and outcomes of the small business policy.

\section{Conclusion and contribution of the paper}

As a developing country, South Africa needs an effective policy that will create a favourable environment for small businesses to prosper. The age of a business venture has certain implications for a small business policy, because it has to accommodate the array of needs of startup and established businesses. Local differences within a country require that policies be designed to adapt to the area. From the literature, the study hypothesised whether the small business policy acknowledges the age and location of a business.

The results of the study show that only the location (the metropolitan municipality where the business is located) has a statistically significant effect on the objectives, outputs and outcomes of the small business policy. The age of the business has no effect. The results imply that the location of the start-up / established business owners does affect their standpoint on the objectives of the small business policy. The objectives are viewed and interpreted differently in the different provinces and therefore in the different metropolitan municipalities. Start-up and established 
business owners expect similar outputs such as finance and incentives that have to reach all regions of the country to assist with their business endeavours. Outcomes such as improving the regulatory environment and decreasing business start-up obstacles are perceived differently in the different metropolitan municipalities.

The findings of the study increase understanding of the small business policy in terms of its appropriateness for the age of a business. They confirm that location plays a key role in shaping small business and entrepreneurial activities. This should help government refine formulation and design of policies.

The contribution of this study is to supplement the sparse literature available on evaluating the objectives, outputs and outcomes of small business and entrepreneurship policies. This study provides additional insights, thus adding to the knowledge base of the different fields of small business, entrepreneurship and the policy environment. Additionally, the study makes a contribution by investigating and comparing how the selected metropolitan municipalities' small business policy affects start-up and established businesses. From a practical perspective, this paper should assist both national and international policymakers to identify specific context-bound interventions relevant to businesses' location.

\section{$7 \quad$ Limitations and recommendations}

No study is without limitations. Firstly, policy research is often hampered by the sensitive and confidential nature of the research topic. Secondly, on a methodological level, in this study the sampling methods used were a combination of probability (systematic) and non-probability (purposive) sampling. The latter required the researcher's own judgment in the selection of respondents. This may have subjected the data to researcher bias. Thirdly, from the three provinces included in this study, the majority of responses were Gauteng-based which means that that province was overrepresented and might have contributed towards response bias. Fourthly, the geographical context (i.e. South Africa) of the research could restrict the generalisability of the findings to other contexts. However, country-specific research in this regard was the only possible option for the researcher, due to constraints in terms of information, finance and time.

The following recommendations can be made to minimise the limitations. Firstly, due to a lack of information on small business policy evaluation, studies on compiling evaluation criteria and plans need further research. This would include criteria such as deciding what to evaluate, when and how to carry out the evaluation; benchmarking evaluation results and feeding results back into future policy design. Secondly, it would be preferable to use only one sampling method instead of a combination of methods to ensure consistency with the selection of respondents. Thirdly, the sample size for each province should be increased to obtain a fuller representation from all three provinces. In future research the remaining six provinces in South Africa should also be included. This would allow for provincial comparisons which may result in constructive findings to help inform policy decisions. South Africa is an emerging economy and well-developed policies are necessary for its continued economic growth. Fourthly, peer countries' small business policies could be thoroughly investigated to extract lessons from which South Africa could learn and benefit.

\section{References}

ACS, Z.J. \& SZERB, L. 2006. Entrepreneurship, economic growth and public policy. Small Business Economics, 28:109-122. Available at: http://0-w.springerlink.com.innopac.up.ac.za/content/ 9670541t2j372251/ [accessed December 2007].

AUDRETSCH, D.B. 2005. The emergence of entrepreneurship policy. Published in Audretsch, D.B., Grimm, H., \& Wessner, C.W. (eds.) Local heroes in the global village: Globalization and new entrepreneurship policies. International Studies in Entrepreneurship, 7. New York: Springer. BOTHA, M. 2014. The entrepreneur. Published in Nieman, G.H. \& Nieuwenhuizen, C. 2014. Entrepreneurship: A South African perspective (3rd ed.) Pretoria: Van Schaik. 
BRUTON, G.D., AHLSTROM, D., \& OBLOJ, K. 2008. Entrepreneurship in emerging economies: Where are we today and where should the research go in the future? Entrepreneurship Theory and Practice, 32(1):1-14. BRYNARD, P.A. 2007. The policy gap in South Africa. Journal of Public Administration, 42(3),357-364. CLOETE, F. 2009. Evidence-based policy analysis in South Africa: Critical assessment of the emerging government-wide monitoring and evaluation system. Journal of Public Administration, 44(2):294-311. COOPER, D.R. \& SCHINDLER, P.S. 2011. Business research method. (11 ${ }^{\text {th }}$ ed.) USA: McGraw-Hill. DPLG (Department of Provincial and Local Government), 2006. Stimulating and developing sustainable local economies. National framework for Local Economic Development (LED) in South Africa (2006-2011). http://www.dplg.gov.za [accessed November 2007].

DIAMANTOPOULOS, A. \& SCHLEGELMILCH, B.B. 2000. Taking the fear out of data analysis. United Kingdom: South-Western Cengage Learning.

DTI (DEPARTMENT OF TRADE AND INDUSTRY). 1995. White paper on national strategy for the development and promotion of small business in South Africa. South African Government Information.

DTI (DEPARTMENT OF TRADE AND INDUSTRY). 2005a. Integrated small-enterprise development strategy: A summarised version. Unlocking the potential of South African entrepreneurs. Available at: http://www.dti.gov.za [accessed July 2007].

DTI (Department of Trade and Industry), 2005b. Integrated strategy on the promotion entrepreneurship and small enterprises: Unlocking the potential of South African entrepreneurs. Available at: http://www.dti. gov.za [accessed March 2009].

ENGELA, R. \& AJAM, T. 2010. Implementing a government-wide monitoring and evaluation system in South Africa. Evaluation Capacity Development (ECD) Working Paper Series. No. 21. Independent Evaluation Group. Washington, DC: The World Bank. Available at: www.worldbank.org/ieg/ecd [accessed January 2010].

GED (Gauteng Economic Development), 2013. Gauteng leads in economic development, jobs, youth empowerment and skills training. Available at: http://www.info.gov.za/speech/ [accessed September 2013]. GWIJA, S.A., ERESIA-EKE, C. \& IWU, C.G. 2014. Assessing the impact of support structures and initiatives to youth entrepreneurship development in a selected township in the Western Cape Province in South Africa. Mediterranean Journal of Social Sciences, 5(1):61-68.

HEMPHILL, T.A. 2005. National technology entrepreneurship policy: Foundation of a network economy. Science and Public Policy, 32(6):469-478.

HERRINGTON, M., KEW, J. \& KEW, P. 2010. GEM (Global Entrepreneurship Monitor): 2009.

South African report - With a difference. Tracking entrepreneurship in South Africa: A GEM perspective. Cape Town: University of Cape Town Graduate School of Business.

IJEOMA, E.O.C. \& MATARIRANO, O. 2011. Government subsidised financial assistance to small scale businesses: A comparative analysis of Namibia, South Africa and Zimbabwe. Journal of Public Administration, 46(1.1):854-867.

ILE, I.U., ERESIA-EKE, C. \& ALLEN-ILE, C. 2012. Monitoring and evaluation of policies, programmes and projects. Pretoria: Van Schaik Publishers.

KIRBY, D.A. 2005. Book review: LUNDSTRÖM, A. \& STEVENSON, L.A. (eds.) 2005. Entrepreneurship policy: Theory and practice. New York: Springer. International Entrepreneurship and Management Journal, 1:557-559.

LIGTHELM, A.A. 2013. Confusion about entrepreneurship? Formal versus informal small businesses. Southern African Business Review, 17(3):57-75.

LUIZ, J. \& MARIOTTI, M. 2011. Entrepreneurship in an emerging and culturally diverse economy: A South African survey of perceptions. South African Journal of Economics and Management Sciences, 14(1): 47-65.

LUNDSTRÖM, A. \& STEVENSON, L. 2001. Entrepreneurship policy for the future. Stockholm, Swedish Foundation for Small Business Research.

LUNDSTRÖM, A. \& STEVENSON, L.A. 2005. Entrepreneurship policy: Theory and practice. New York: Springer.

MINNITI, M. 2008. The role of government policy on entrepreneurial activity: Productive, unproductive, or destructive? Entrepreneurship Theory \& Practice, September:779-790. 
NIEMAN, G.H. \& NIEUWENHUIZEN, C. 2014. Entrepreneurship: A South African perspective $\left(3^{\text {rd }}\right.$ ed.) Pretoria: Van Schaik.

NISKA, M. \& VESALA, K.M. 2013. SME policy implementation as a relational challenge. Entrepreneurship \& Regional Development: An International Journal, 25(5-6):521-540. Available at: http://dx.doi.org/ 10.1080/08985626.2013.798354 [accessed January 2014].

PETERS, R. \& NAICKER, V. 2013. Small, medium, micro enterprise business goals and government support: A South African case study. South African Journal of Business Management, 44(4):13-24.

PEYPER, L. 2012. How SME-friendly are SA's cities? Finweek, 04 October. Available at: http://finweek. com/2012/10/04/how-sme-friendly-are-sas-cities/ [accessed October 2013].

POLICY HUB. 2010. Magenta Book. Chapter 1: What is policy evaluation? Available at: http://www.nationalschool.gov.uk [accessed September 2010].

ROBSON, P.J.A., WIJBENGA, F. \& PARKER, S.C. 2009. Entrepreneurship and policy: Challenges and directions for future research. International Small Business Journal, 27(5):531-535. Available at: http://isb.sagepub.com/content/27/5/531 [accessed January 2014].

RSA (Republic of South Africa), 1996. The National Small Business Act (Act No. 102 of 1996). Pretoria, Government Printer.

STEVENSON, L. \& LUNDSTRÖM, A. 2007. "Dressing the emperor: The fabric of entrepreneurship policy”. Publisched in Audretsch, D.B., Grilo, I. \& Thurik, R. (eds.) 2007. Handbook of Research on Entrepreneurship Policy. Great Britain: Edward Elgar.

THEMBA, Y. 2012. Small is the way to go. Sunday Times, Review, 01 July:5.

THORPE, R., HOLT, R., MACPHERSON, A. \& PITTAWAY, L. 2005. Using knowledge within small and medium-sized firms: A systematic review of the evidence. International Journal of Management Reviews, 7(4): 257-281.

TURTON, N. \& HERRINGTON, M. 2013. Global entrepreneurship monitor 2012: South Africa.

Cape Town: University of Cape Town.

VAN STEL, A., STOREY, D. \& THURIK, R. 2007. The effect of business regulations on nascent and actual entrepreneurship. Discussion Papers on Entrepreneurship, Growth and Public Policy, 28(2-3):171-186.

VAN VUUREN, J.J. \& GROENEWALD, D. 2007. A critical analysis of the influence of start-up factors in small businesses and entrepreneurial ventures in South Africa. Acta Commercii, (1):269-280. Available at: https://innopac.up.ac.za [accessed February 2008].

WATSON, T.J. 2013. Entrepreneurship in action: Bringing together the individual, organisational and institutional dimensions of entrepreneurial action. Entrepreneurship \& Regional Development: An International Journal, 25(5-6):404-422. Available at: http://dx.doi.org/10.1080/08985626.2012.754645 [accessed January 2014].

WESTHEAD, P. WRIGHT, M. \& MCELWEE, G. 2011. Entrepreneurship: Perspective and cases. United Kingdom: Prentice-Hall. 
Annexure A: Small business policy objectives

Assist with business venture growth.

Motivate more new entrepreneurs to start businesses.

Target existing businesses rather than individuals.

Target nascent entrepreneurs / new business starters

Focus on creating a favourable business environment (by, for example, reducing red tape).

Stimulate entrepreneurship and an entrepreneurial culture or climate in the country.

Achieve results in less than four years.

Have a narrow, rather than a broad definition of which institutional structures constitute the support environment.

Favour measures to support early phases of the entrepreneurial development process.

Influence the quantitative aspects such as the number of self-employed, small or new business ventures rather than the quality thereof.

Annexure B: Small business policy outputs

Support reaches all regions of the country because the local network for small business development services has been strengthened.

The necessary support incentives are provided

A dedicated network of SMME finance has been established.

\section{Annexure C: Small business policy outcomes}

\section{A demand has been created for small-enterprise products and services.}

Small enterprise competencies and delivery capacity have improved.

Enterprise networks, for example, between government, public institutions and the private sector, have strengthened.

The regulatory environment has improved.

Entrepreneurship and small business research have improved.

An entrepreneurship culture has been fostered

The number of business start-ups has increased.

The number of start-up obstacles has decreased.

There are changes in the level of entrepreneurial activity amongst women and the youth. 